\title{
Siphonophoridae from Brazilian Amazonia. Part 2 - Two new tree- climbing species of the genus Siphonophora, including one showing pilosity polymorphism (Diplopoda, Siphonophorida)
}

\author{
Helen J. READ ${ }^{1, *}$ \& Henrik ENGHOFF ${ }^{2}$ \\ 12 Egypt Wood Cottages, Farnham Common, Bucks, SL2 3LE UK. \\ ${ }^{2}$ Natural History Museum of Denmark, University of Copenhagen, \\ Universitetsparken 15, DK-2100 Copenhagen Ø, Denmark. \\ "Corresponding author: helen@helen-read.co.uk \\ 2Email: henghoff@snm.ku.dk \\ ${ }^{1}$ urn:lsid:zoobank.org:author:30F92B0D-B214-44AA-9508-C0042D6BB628 \\ ${ }^{2}$ urn:lsid:zoobank.org:author:FB09A817-000D-43C3-BCC4-2BC1E5373635
}

\begin{abstract}
This is the second part of a study of a large collection of Siphonophoridae Cook, 1895 from Brazil. Here, those without an abrupt division between the head and rostrum are considered. Two species have been distinguished and are described as Siphonophora setaepromissa sp. nov. and S. tuberculata sp. nov. Siphonophora hebetunguis (Attems, 1951) from the same region has many similarities with the two new species and is redescribed from type material. Comparisons have also been made with S. fuhrmanni Carl, 1914, and comments are made on the genera Cordillerium Verhoeff, 1941, Pterozonium Attems, 1951, Rhinosiphora Verhoeff, 1924, and Siphonophora Brandt, 1837. Finally, some suggestions for characters to look at in future collections of siphonophorids are made based on experience of this collection.
\end{abstract}

Keywords. Siphonophorida, Siphonophoridae, Brazil, Amazonia.

Read H.J. \& Enghoff H. 2019. Siphonophoridae from Brazilian Amazonia. Part 2 - Two new tree-climbing species of the genus Siphonophora, including one showing pilosity polymorphism (Diplopoda, Siphonophorida). European Journal of Taxonomy 496: 1-26. https: //doi.org/10.5852/ejt.2019.496

\section{Introduction}

Read \& Enghoff (2018) provided an introduction to the poorly known order Siphonophorida Newport, 1844 and also to the large collection from Brazil collected by the late Joachim Adis (see Wolf \& Adis 1992 for a map showing the localities mentioned in the text). Two groups of species could be distinguished, one of which was attributed to the genus Columbianum Verhoeff, 1941 and was discussed by Read \& Enghoff (2018), and one which is addressed here.

Whereas Columbianum, as detailed by Read \& Enghoff (2018), is distinguished by a clear demarcation between the head and rostrum, the remaining specimens in the collection have a more gradual transition 
both in lateral and dorsal views. This head shape is not necessarily completely smooth and may be 'sinuous' laterally, but the demarcation is never as abrupt as in Columbianum, and the head is never domed. The rostrum may be slightly curved ventrad and in this respect resembles the beak of a bird, rather than the tusk of a narwhal. Other differences are:

- the antennae are more or less the same length as the rostrum. They may stretch just beyond the tip or are just shorter than it (dependent mostly on the state of preservation, cf. Read \& Enghoff 2018) but are never substantially longer, as seen in Columbianum.

- perhaps, partly as a consequence of the shorter length, the antennae also appear to be rather more chunky, with the antennomeres mostly broader than long.

- the anterior edge of the collum may have a gentle curve, but never appears to have a deeply incised $\mathrm{V}$. The collum shape is clearly visible under SEM, but can appear to be V-shaped with a cursory look under a light microscope.

- accessory claws are present, but they are not especially large (as in Columbianum); however, the claw itself may be expanded into a broad 'paddle-like' structure.

There are similarities between the two groups, notably the pubescent covering of setae and abundant tubercles. As in the majority of siphonophorids, the gonopods are very similar among species, and it can be difficult to determine if male specimens are mature or juvenile. As noted previously (Read \& Enghoff 2018), SEM of the gonopods does not generally yield helpful information to distinguish between species because they are so variable within species/growth stages.

Further analysis of the entire family Siphonophoridae is needed so that generic characteristics may become clearer; however, despite the uncertainty about the genus, we feel that this current group of species are worthy of publication at the present time because they add to our knowledge about intraspecific variability and provide some information about the ecology of this group. One of the new species presents a type of polymorphism (very long pilosity in some but not all males) never before encountered in any millipede. In addition, our study also evaluates characters that may be helpful for species determination. This paper therefore reviews those species currently considered to be of the genus Siphonophora found in the Brazilian Amazonia.

\section{Material and methods}

A total of 294 individual specimens were observed using light microscope (Nikon SMZ 2B), and a range of characters were described and measured. Scanning Electron Microscopy (SEM) using a JEOL JSM$6335 \mathrm{~F}$ was used to observe microscopic details of the cuticle and the gonopods. Parts of some specimens (such as legs and antennae) were temporarily mounted on slides. The female vulvae were not examined in detail. Full details of the characters and terminology used in the species descriptions are given in Read \& Enghoff (2018). See also Read \& Enghoff (2009) for a discussion of the reliability of characters observed both here and in previous studies.

Type specimens of Rhinosiphora hebetunguis Attems, 1951 were obtained from Naturhistorisches Museum Wien; this species of siphonophorid was described from Brazil and is similar to those in the current collection. Specimens of Siphonophora fuhrmanni Carl, 1914 (type) and S. mjoebergi Verhoeff, 1924 (non-type), type species of the nominal genera Cordillerium Verhoeff, 1941 and Rhinosiphora Verhoeff, 1924, respectively, were examined at the Natural History Museum in London.

\section{Repositories for specimens are indicated as follows}

INPA = Instituto Nacional de Pesquisas da Amazônia

NHMD $=$ Natural History Museum of Denmark 
NHML $=$ The Natural History Museum, London

NHMW $=$ Naturhistorisches Museum Wien

ZMUM $=$ Zoological Museum of the State University of Moscow

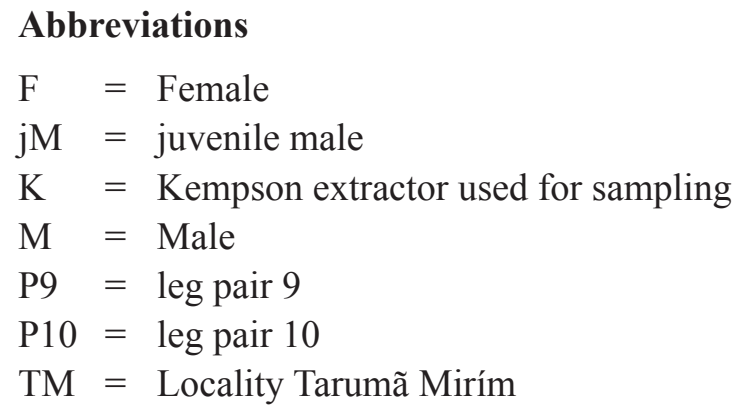

\section{Results}

Class Diplopoda de Blainville in Gervais, 1844

Order Siphonophorida Newport, 1844

Family Siphonophoridae Cook, 1895

Genus Siphonophora Brandt, 1837

See the Discussion chapter concerning the uncertainties surrounding this genus. Of the four known Brazilian species referred to Siphonophora, S. hebetunguis and the two new species described here share an unusual, paddle-like shape of the claws. Considering the unsatisfactory state of siphonophorid genus-level classification, we refrain from suggesting that this character might warrant the recognition of a separate genus.

Siphonophora hebetunguis (Attems, 1951)

Figs $1-2,9 \mathrm{~A}$

Rhinosiphora hebetunguis Attems, 1951: 228.

Siphonophora hebetunguis - Jeekel 2001: 59.

\section{Diagnosis}

Small, pale species with paddle-shaped claws, generally very tuberculate on head, collum, metazonites and coxae. Ventral margin of pleurites almost straight, hind margin with some tubercles. Accessory claw short and arising from lateral side of the claw. Anterior gonopods short and squat, with no spines or other structures at the tip.

\section{Etymology}

A noun in apposition from the Latin 'hebe', meaning 'blunt' or 'dull' and 'unguis', meaning 'claw' and referring to the shape of the claw. Note that in the original description the spelling hebetungis appears, although the key and figure legends use the spelling hebetunguis. The type series from Vienna is labelled hebetungis. As 'unguis' means 'claw' and the claw shape is referred to in the description, it appears that the use of 'hebetungis' is probably a lapsus calami and that the spelling hebetunguis can be taken as correct. 


\section{Material examined}

None of the material is labelled as types, and all the specimens should be considered as syntypes. Two microscope slides, containing the head, first seven body rings, telson, and anterior and posterior gonopods, in combination with a separate body in fluid, constitute a potential lectotype, but we refrain from formally designating it as such. The original description does not list the number of specimens, although both males and females were obviously present.

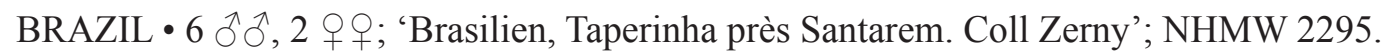

\section{Redescription}

Mostly made from the non-mounted specimens, as the slides are so cleared that most structures are not easily visible.

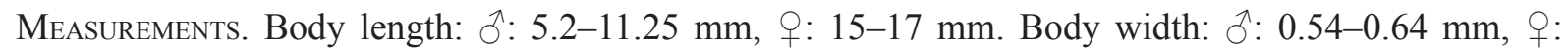
$0.88 \mathrm{~mm}$. Number of podous tergites: $\widehat{\jmath}: 33-50$,, : $57-62$. Number of apodous tergites: $\widehat{0}: 0$, $q: 1-2$.

Colour. Pale cream (but may be due to state of preservation).

Body SHAPE. More or less parallel-sided.

HEAD. In dorsal view showing sinuous or stepped outline laterally between antennal bases and base of rostrum. In lateral view almost flat, with slight demarcation between rostrum and rest of head. Rostrum very slightly downwardly curved. Length of rostrum (to antennal base): $\delta^{\lambda}: 0.34-0.56 \mathrm{~mm}, 0$ : $0.42-$ $0.56 \mathrm{~mm}$. Width of head (between antennal sockets): $\sigma^{\lambda}: 0.20 \mathrm{~mm}, 0$ : $: 0.24-0.26 \mathrm{~mm}$. Abundant setae and tubercles on head. Long setae on gnathochilarium at base of rostrum, some of which reach to rostrum tip.

AntennAe. Appearing more or less the same length as rostrum but exact length not analysed, nor length:width ratio of segments. Sensory pits on antennomeres 5 and 6 present but not especially clear or large.

Collum. Wide, anterior margin with a gentle curve for anterior margin (not examined in SEM). Posterior margin more or less straight. With abundant setae and tubercles.

Tergite 2. More than $0.5 \times$ length of collum.

Mid-BODY RINGS. When plotted (Fig. 1) this species has a small body size and relatively few rings in the males, but there are not enough females to give a clear picture. Paranota not obvious. Slightly castellated, especially anteriorly. Relative width of pro- and metazonites $0.83-0.95$. Prozonites with tubercles, but no setae, metazonites with abundant setae, none long, and tubercles. Prozonite with a channel-like area just in front of the border with the metazonite. Limbus very clearly crenulated under SEM. Ventral margin of pleurites almost straight, although with slightly bilobed margin in anterior few rings. Hind edge of pleurite from inside with clear but irregular tubercles, not serrate but with some setae. Ozopores very difficult to see. The original description does not report on which ring they start, but they were said to be on small protuberances; this may well be due to the state of preservation. In specimens viewed here, the protuberances were not obvious.

LEGS. Length relative to body height and length:width ratio of podomeres not analysed. Coxae tuberculate. Claw broadly expanded and paddle-shaped on anteriormost legs of males and females; by approximately leg pair 80 becoming more conventionally claw-shaped. Accessory claw: short, $1 / 4-1 / 3$ length of claw, quite broad and with rounded tip, arising from lateral side of claw. 
READ H.J. \& ENGHOFF H., The genus Siphonophora from Brazil
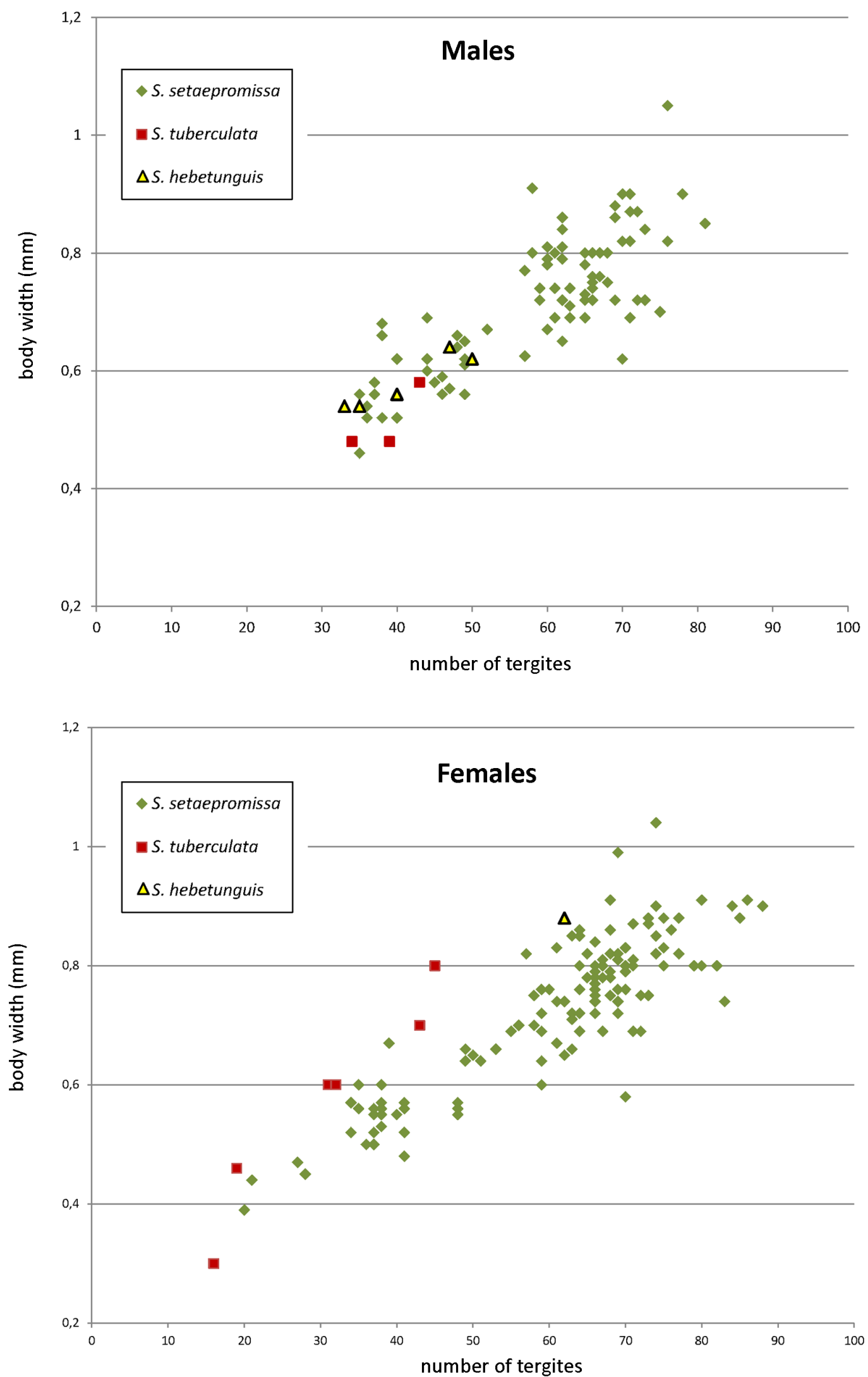

Fig. 1. Relationship between body width $(\mathrm{mm})$ against the total number of tergites with legs for new species of Siphonophora Brandt, 1837 and S. hebetunguis (Attems, 1951). 


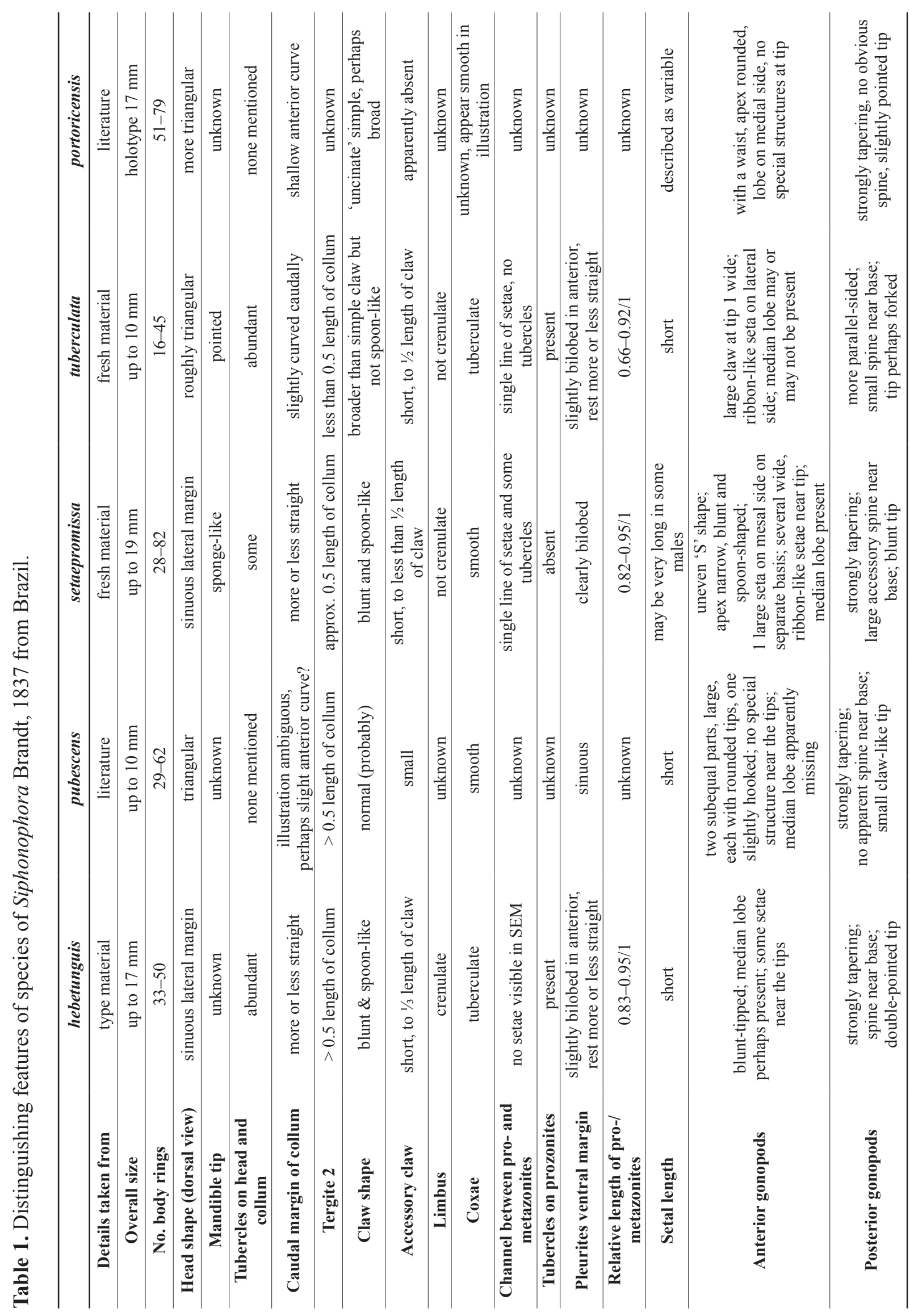


Telson. Length:width ratio 0.42-0.6.

ANTERIOR MALE LEGS (pairs 1-8). Appear normal.

ANTERIOR GONOPODS (Fig. 2D). Short and squat, with segments evidently fused together so exact number is difficult to see. Pair of gonopods appearing like two cupped hands with the cup facing ventrad. Ventral surface with setae but lateral surface without. No apparent enlarged setae or other structures at tip of
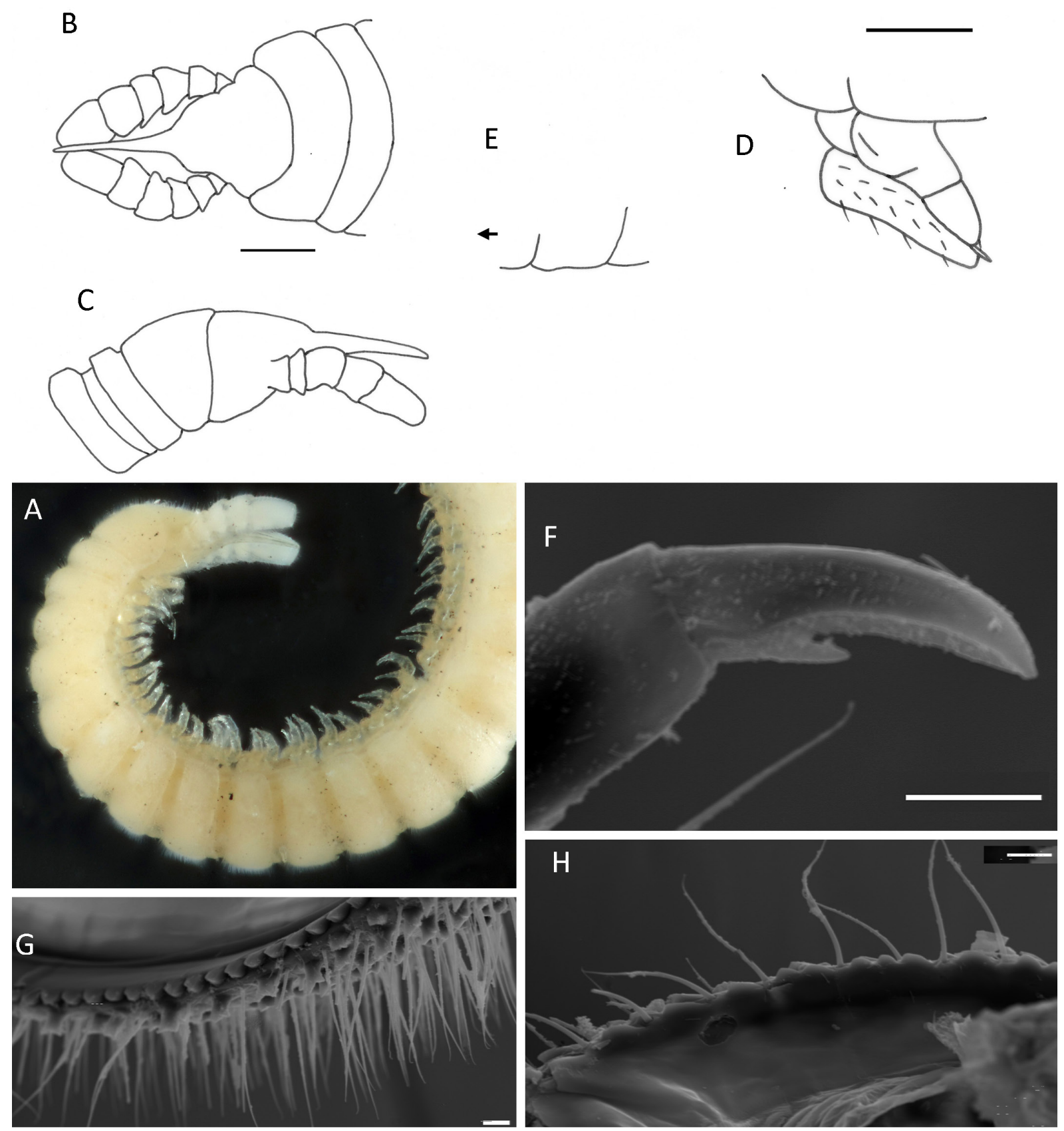

Fig. 2. Siphonophora hebetunguis (Attems, 1951), type specimen (NHMW 2295). A. Head and anterior rings, body width approximately $0.8 \mathrm{~mm}$. B. Head in dorsal view. C. Head in lateral view. D. Male gonopods. E. Ventral margin of pleurite in lateral view, anterior to left. F. Claw. G. Mid-body limbus of male. H. Mid-body pleurite hind edge from inside (male). Scale bars: A $=800 \mu \mathrm{m}$; B-E $=200 \mu \mathrm{m}$; $\mathrm{F}-\mathrm{H}=10 \mu \mathrm{m}$. 
anterior gonopods, including in slide-mounted syntype (note that in those illustrated in Fig. 2D tip of a posterior gonopod protrudes, looking like a structure at tip of anterior gonopods).

Posterior GONOPODS. Not visible in situ in any specimens but original illustrations showed it to be of 'typical' siphonophorid type with last segment long, thin, with spine towards base and a simple doublepointed tip. Slide mount shows spine, although tip is not clear.

\section{Remarks}

All specimens were found at the same time of the year at the same location. The original description of $R$. hebetunguis describes ozopores situated on slight protuberances. However, in all the species described here (and in species of Columbianum as well, Read \& Enghoff 2018) the ozopores are surrounded by a ring of setae. As noted earlier, this can sometimes give the appearance of the ozopores protruding. Examination of various species in the Natural History Museum in London revealed some with clear paranota, for example $S$. longirostris Silvestri, 1895, unlike in any of those in the current collection. See Table 1 for a comparison of the features of S. hebetunguis and the other species of Siphonophora from Brazil, as well as S. portoricensis Brandt, 1837.

The new species described below differ from S. hebetunguis in the structure of the anterior gonopods as well as in some other somatic characters. They do, however, have claws that are shaped similar to those described for hebetunguis.

Siphonophora pubescens Schubart, 1947

Diagnosis (translated from Schubart 1947)

Body length 5.5-10 mm, width $0.6-0.7 \mathrm{~mm}$. Yellowish brown: the first 10 to 20 tergites more reddish, rostrum and antennae pale yellowish tinted, usually darker prozonites, the ventral side and legs pale. Some specimens very dark. Head covered with fine bristles, rostrum elongated to medium length, reaching almost the end of the antennae. Rostrum with 2 bristles near the base and some short ones on the distal part. Thick antennae; the $7^{\text {th }}$ antennomere protected by the $6^{\text {th }}$. Antennomeres 5 and 6 with fields of sensilla.

\section{Material examined}

None.

\section{Remarks}

This species was described from Brazil (the state of Pará). The original description is good and includes several clear drawings. The head shape of this species is 'gradual', although in dorsal view it is very triangular and does not appear to have a sinuous lateral margin where the antennae are inserted. The posterior gonopods are very simple, similar to those of $S$. hebetunguis in having a spine partway along, but ending in a reduced claw. The anterior gonopods, however, are quite different, consisting of two parts, which Schubart considered to be a solenomerite and a prefemoral process, which is completely unlike conditions in any of the species described here. Siphonophora pubescens also has setae on the coxae of the anterior gonopods, and the gonopods appear rather differently aligned in relation to the sternum. It is similar in having smooth coxae, as in S. setaepromissa sp. nov., and the pleurite margin is sinuous, with small tubercles and short hairs.

This species is similar to $S$. portoricensis in the rough shape of the anterior gonopods, which also have a mesal lobe on the mesal side. In addition, the coxae of the first pair of legs have medial projections, as in S. setaepromissa sp. nov. 
Siphonophora setaepromissa sp. nov.

urn:1sid:zoobank.org:act:4C3C08E9-C6F9-464C-8E01-A9D0399F769D

Figs 1, 3-6, 8C, 9B

\section{Diagnosis}

A medium-sized species, although very variable, with paddle-shaped claws. Very setose (and some males with very long setae on metazonites), but not especially tuberculate and coxae smooth. Pleurite ventral edge clearly bilobed, hind margins with some tubercles. Accessory claw short and arising from the ventral side of the claw. Anterior gonopods relatively long, with spines at the apex and a projection mesally.

\section{Etymology}

The specific name, meaning uncut or unruly setae, refers to the long setae on some of the males

Material studied (total: $96 \hat{\jmath} \widehat{\partial}, 152 \uparrow+$ )

\section{Holotype}

BRAZIL • गे; Amazonas Province, Rio Tarumã Mirím, Igapó, inundation forest; $03^{\circ} 02^{\prime} \mathrm{S}, 60^{\circ} 17^{\prime} \mathrm{W}$; TM50C; 2 Sep. 1976; J. Adis leg.; INPA.

\section{Paratypes}

BRAZIL $\bullet 1 \hat{\partial}, 1$; s same collecting data as for preceding; ZMUM $\bullet 4 \hat{\jmath}, 5$ q $O$; same collecting data as for preceding; INPA 11 ; same collecting data as for preceding; NHMD • $7 \lesssim \precsim, 6$ 우; same

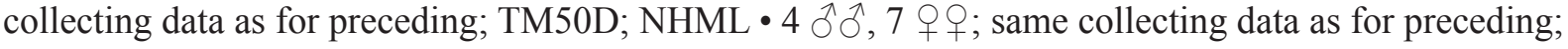
TM50B; NHMD.

\section{Referred non-type material}

Approximately 40 collections examined as part of this study can be attributed to this species. They are all from the same locality with dates ranging from 16 Sep. 1975 to 12 Jun. 1987. Most were from photoeclectors collecting invertebrates walking up or down trees. A small number from 1987 were collected as part of a study of standing crop, but from the same location. Specimens have been distributed between INPA, NHMD, NHML, NHMW and ZMUM.

\section{Description}

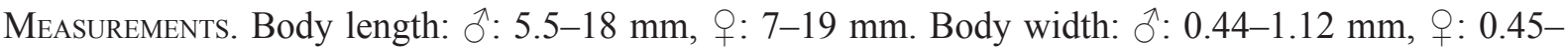

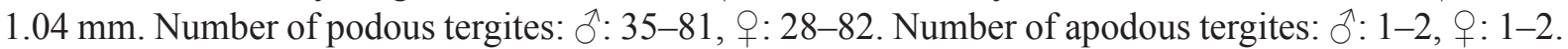

CoLour. Yellow to pale brown, some specimens slightly darker, especially dorso-laterally on prozonites. Small specimens generally uniformly pale white/yellow.

BODY SHAPE. Generally parallel-sided, widest point just slightly posterior of mid-point. Some narrowing behind head and towards the telson.

HEAD. In dorsal view, more or less triangular in shape, with slight depressions for the bases of the antennae, rostrum relatively clearly demarcated from rest of head. In lateral view, dorsally gradually tapering from top of head to tip of rostrum, head not domed and with no clear demarcation between rostrum and rest of head. Rostrum prominent and clear but relatively short, rostrum tip to base roughly same distance as rostrum base to antennal bases. In lateral view, rostrum slightly down-curved relative to rest of head.The 'mouth' was open in one female specimen and was examined under SEM. Mandible tip was sponge-like and fitted into gnathochilarium at base and rostrum at tip. Length of rostrum (to

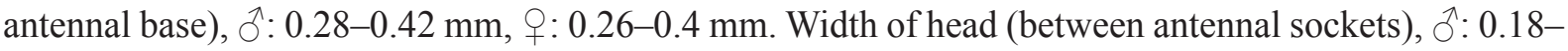


$0.34 \mathrm{~mm}, 0.2-0.28 \mathrm{~mm}$. Head setose and with tubercles laterally and posteriorly, but rather sparse dorsally. Larger setae on gnathochilarium at base of rostrum and smaller ones along sides of rostrum to tip.

ANTENNAE. Approximately of same length as rostrum, generally appearing shorter. Overall length: 0.63$0.82 \mathrm{~mm}$. Length:width ratio of segments $0.92,0.75,0.73,0.76,0.95,1.35$ and 0.47 , antennal cones not measured ( 3 specimens examined). Antennal pits on segments 5 and 6 present and containing sensilla, but smaller and less clear than in species of Columbianum.

ColLum. With abundant setae but no tubercles, although bases of setae situated very closely together, giving it a rugged look. Wide, with anterior margin forming very gentle curve. In some specimens V-shaped margin visible with SEM. Posterior margin almost straight.

TERGITE 2. Narrower than collum but more than $0.5 \times$ length of collum.

MiD-BODY RINGS. When plotted (Fig. 1) this species has a relatively large number of segments for the body width although both increase as overall body size increases. No obvious paranota, although difficult to see in some specimens because of dense cloak of setae. Metazonites standing slightly proud
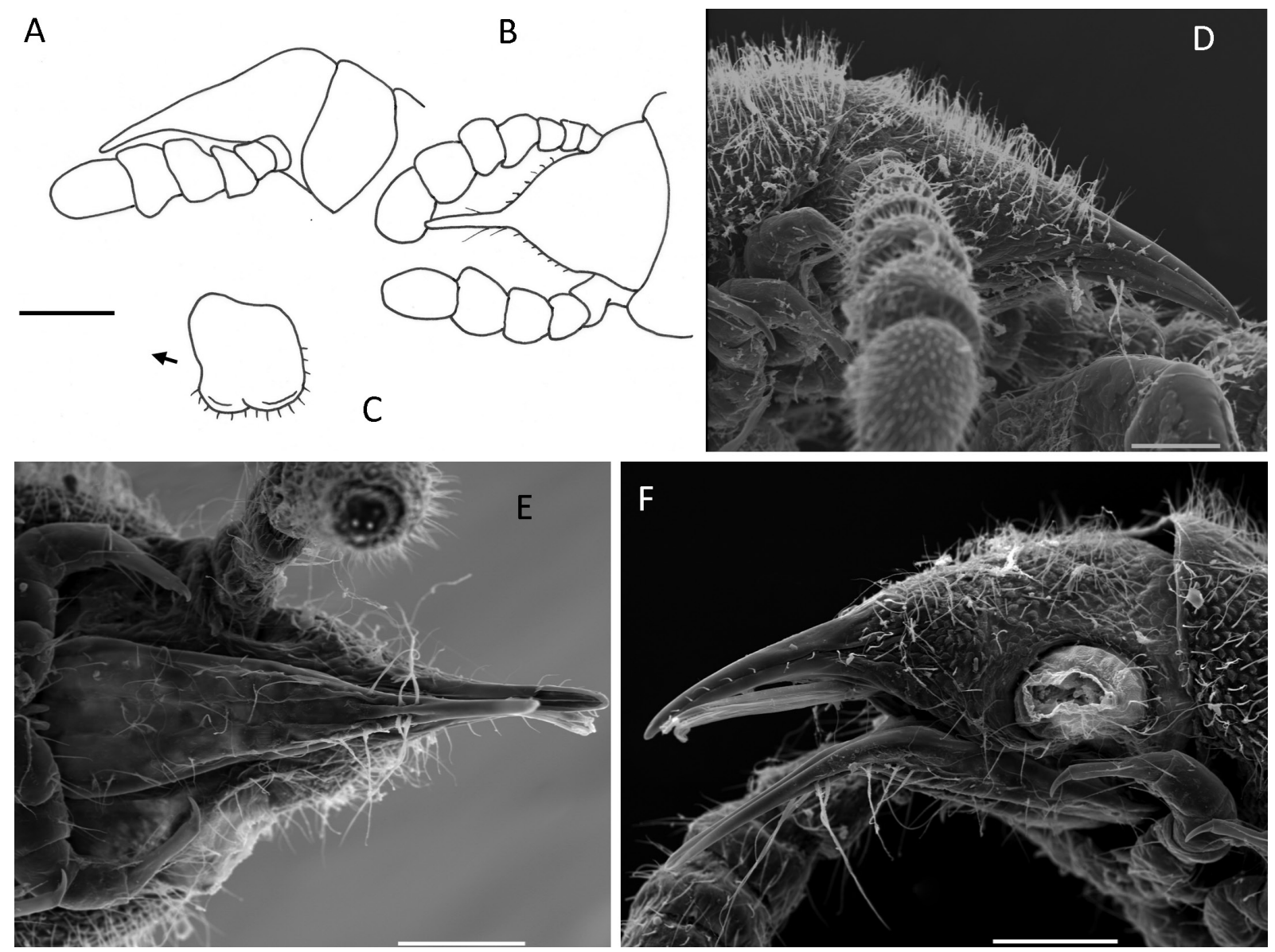

Fig. 3. Siphonophora setaepromissa sp. nov., non-type specimen. A. Head in lateral view. B. Head in dorsal view. C. Pleurite in lateral view, anterior to left. D. Head of male in lateral view. E. Head of female in ventral view. F. Head of female in lateral view with left antenna missing. Scale bars: A-C = $200 \mu \mathrm{m} ; \mathrm{D}-\mathrm{F}=10 \mu \mathrm{m}$. 
of prozonites giving a slight 'castellated' appearance in lateral view, at least anteriorly, posteriorly with less contrast so that dorsal outline is rather more even. Relative width of pro-/metazonites $0.82-0.95$. Mid-body metazonites (from about tergite 20 onwards) in some, mostly larger, males covered in very dense and very long, almost tangled, setae, appearing clearly different to pubescent covering in most other siphonophorids. Especially between body rings $12-20$, setae can be up to $0.31 \times$ body width. Some males and all females have a shorter type of setal covering, some males intermediate (see graph Fig. 4). Metazonites with tubercles, but irregular in both occurrence and structure; may be more pronounced partway along body length. Prozonites lacking setae and quite smooth. Under SEM cytoscutes on prozonites are visible but not very pronounced. Channel between prozonites and metazonites bearing single line of setae and some collapsed tubercles. Limbus with membranous edge and not serrate. Pleurites with clearly bilobed ventral margin supporting setae and few irregular tubercles. Hind edge from inside not serrate. Ozopores starting on tergite 5 and ending on the penultimate. Position along tergal ridge seems variable, generally high above pleura-tergal margin; difficult to see any possible protuberance because of setae. Spiracles appear normal.

LEGS. Length $0.64-0.7$ of body width ( $\overbrace{}^{7}), 0.66$ ( ( ). Length:width ratio of podomeres, prefemur to tarsus (analysed specimens $=5$ ): 1.08-1.4, 1.2-2.0, 0.79-1.18, 1.4-1.64, 3.0-4.3, 1.86-4.3. Coxae without tubercles; coxal pores particularly large in some specimens. Claws of paddle-like shape anteriorly but by leg pair 50 just appearing longer than 'normal'. Extent of this paddle-like shape variable, both between individuals and along the body of a single individual; most pronounced on the anterior legs of larger males but also found to a lesser degree on females and small males. Accessory claw shorter than claw (reaching just less than halfway along) and situated ventrally on claw.

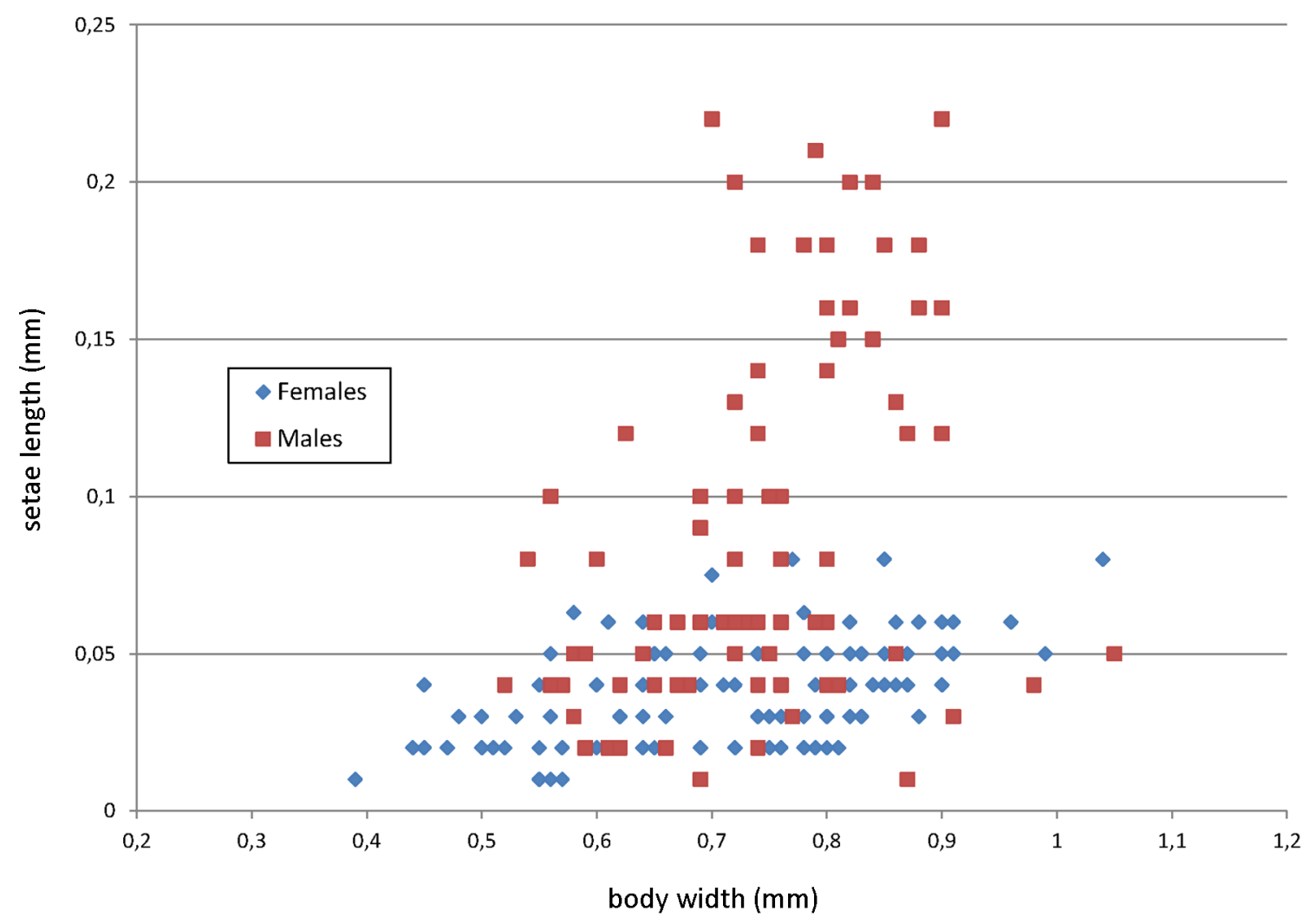

Fig. 4. Siphonophora setaepromissa sp. nov., relationship between body width and setae length in males and females. 
TELSON. Length:width ratio 1.7-1.9.

Anterior male Legs. Legs 1 and 2 with slightly shorter tarsus than normal walking legs.

ANTERIOR GONOPODS. Impossible to determine number of segments, even under SEM, as several appear partially fused. Normally bent into rather uneven S-shaped curve with groove for posterior gonopods to lie in visible under SEM and appearing more or less spoon-shaped towards apex. Several strong and quite long setae on more basal segments of posterior side and probably some on anterior side in same area, but difficult to be sure of their distribution. Median lobe as described by Shelley (1996) for S. portoricensis present on one of basal segments as expansion of distal margin of segment just on mesal side; this is, however, interpreted here as modification of shape of segment to allow complicated flexure and may not be particularly significant. Apical segment smoother in surface texture (unlike wrinkled surface of rest of gonopods), concave and spoon-like in shape. At apex narrowed, blunt-tipped and slightly curved ventrad, forming final curve of S. Strong setae towards rim of 'spoon' but not confined to it, some of these wide and almost 'ribbon-like' in form. One seta, on mesal side, larger than others, on separate base and approximately equal in length to main part of anterior gonopods.

Posterior GONOPODS. Probably with 7 segments including the coxae (and assuming that the apical elongated region is just one). Segment edges easier to determine than in anterior gonopods. Segments irregular in size and shape, several appearing triangular in shape to accommodate strong anterior flexure of almost $90^{\circ}$ (Fig. 6B). No setae apparent on basal segments, although one SEM specimen shows a single seta on posterior side of $4^{\text {th }}$ segment. Apical segment very long and thin, appearing parallel-sided
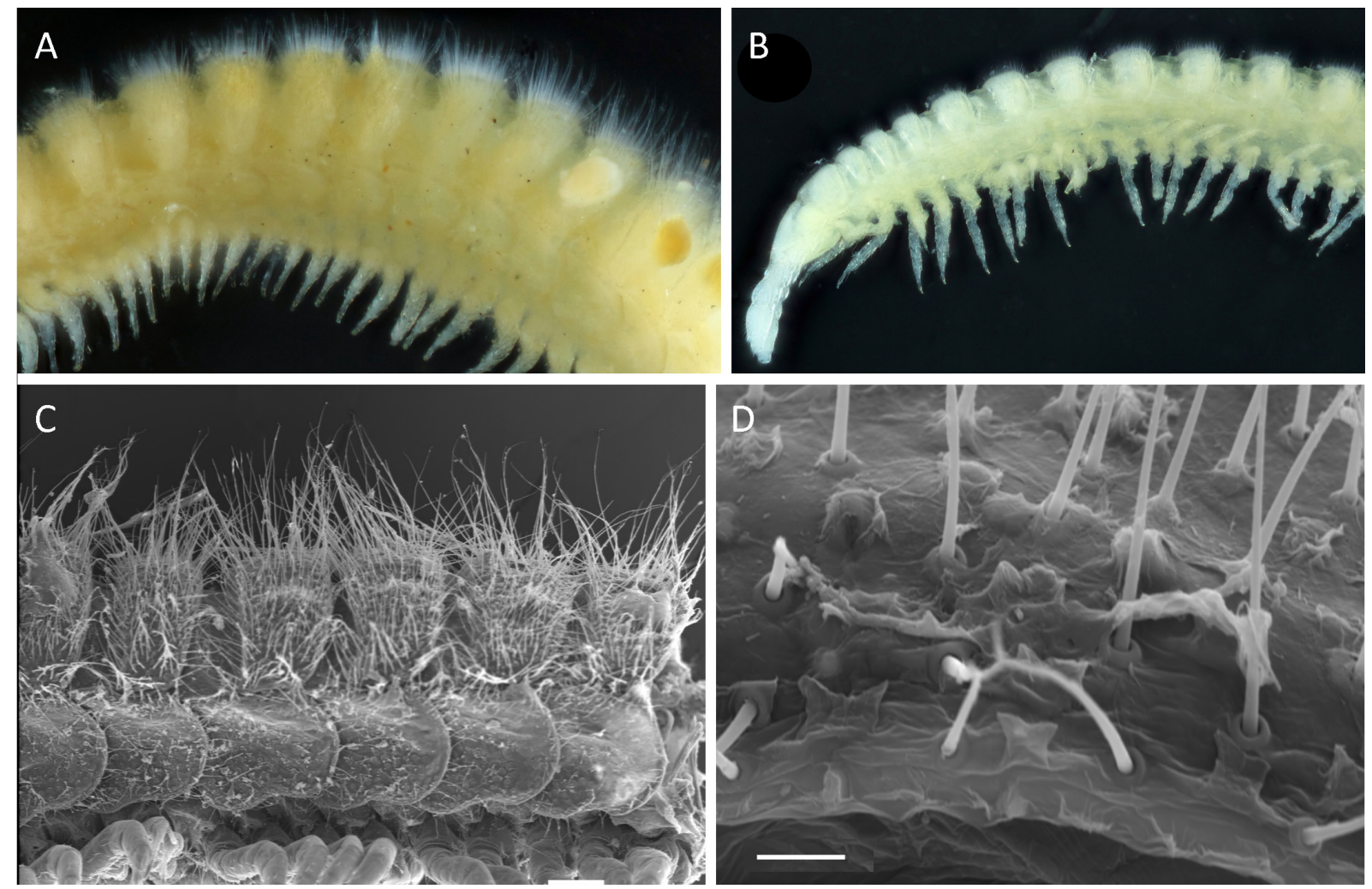

Fig. 5. Siphonophora setaepromissa sp. nov., non-type specimens. A. Mid-body rings of male with long setae, body width approximately $1 \mathrm{~mm}$. B. Midbody rings of male with short setae, body width approximately $1 \mathrm{~mm}$. C. SEM showing long setae in male. D. Limbus of female showing anchor-shaped tubercles. Scale bars: $\mathrm{C}=100 \mu \mathrm{m} ; \mathrm{D}=10 \mu \mathrm{m}$. 
under light microscope but under SEM gently spirally twisted like streamer, with blunt tip and strong accessory spine approximately $1 / 4$ to $1 / 3$ of length from base. No apparent setae on sternal plate from which gonopods arise, although sometimes difficult to see. Gonopods of long-haired males and shorthaired males show no apparent differences. Some of much smaller males also have identical gonopods, although others have slightly shorter tips to anterior gonopods, thus appearing shorter and squatter. The degree of anterior flexure is highly variable. Some gonopods are very tightly bent, others protrude from the body in a more relaxed and much straighter form. This probably depends greatly on the level of preservation of the specimen. In the past it has been considered that larger males showed a greater degree of flexure, but this is not necessarily true of the current collection.

\section{Pilosity polymorphism}

A notable feature of this species is that some males, but not all, have extremely long setae on the middorsal part of the metazonites (Figs 4-5). Initially, this seemed so obvious and distinct that those with the long setae were considered to be a different morphospecies. However, no females were found with
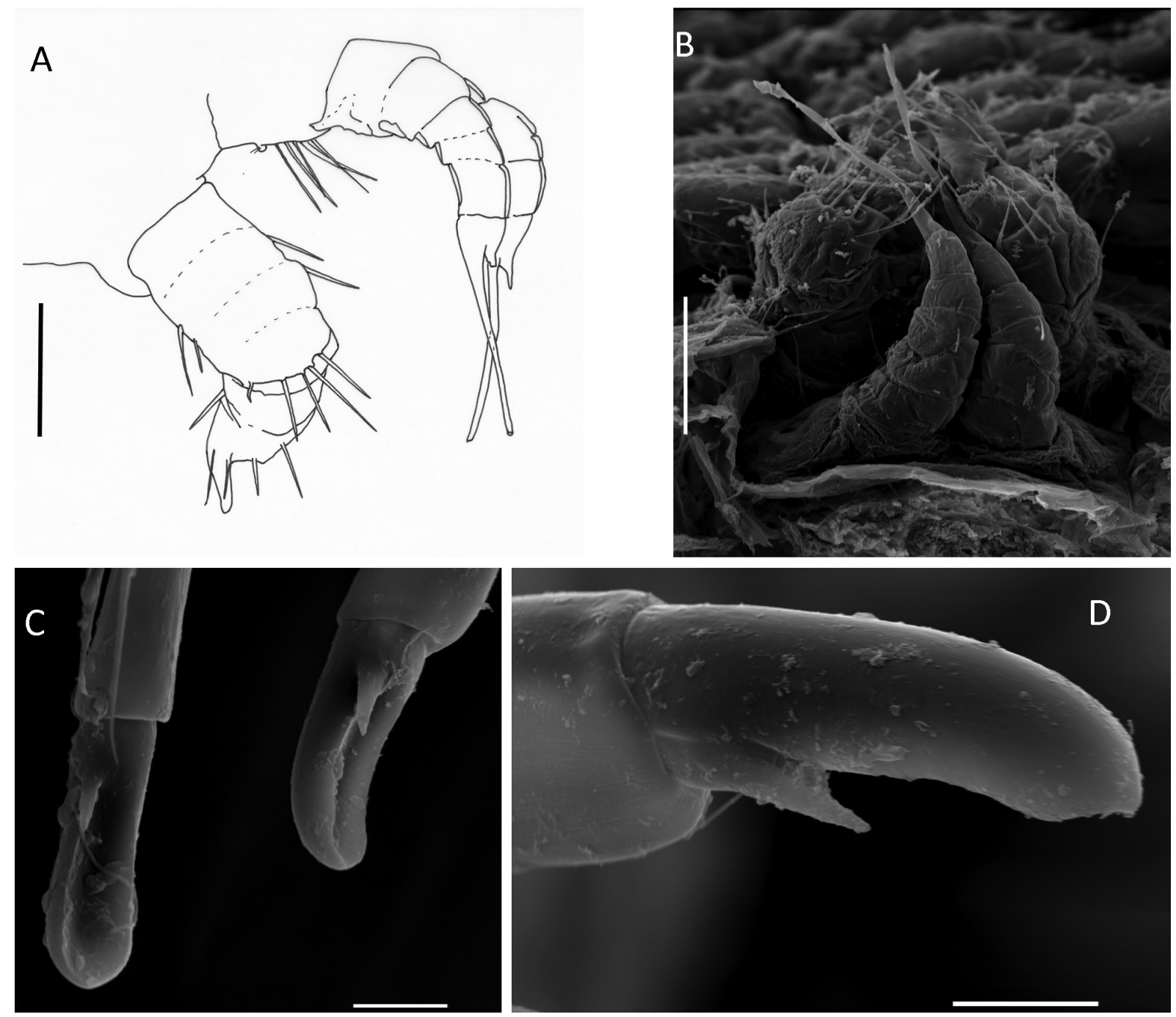

Fig. 6. Siphonophora setaepromissa sp. nov., non-type specimen. A. Male gonopods in situ. B. Male gonopods in situ. C. Claws in ventral view. D. Claw in anterior view. Scale bars: A-B $=100 \mu \mathrm{m} ; \mathrm{C}-\mathrm{D}=$ $10 \mu \mathrm{m}$. 
Table 2. Numbers of S. setaepromissa sp. nov. found at different times of the year, with information about the soil conditions at the time of collection.

\begin{tabular}{lccccc}
\hline Month & F & M & Total & Soil condition & $\begin{array}{c}\text { No. (percentage) of } \\
\text { 'long-haired' males }\end{array}$ \\
\hline January & & & 0 & terrestrial & \\
February & 4 & 4 & 8 & terrestrial & $1(25 \%)$ \\
March & & & 0 & inundated & \\
April & & 1 & 1 & inundated & \\
May & 6 & 1 & 7 & inundated & $1(100 \%)$ \\
June & 14 & 12 & 26 & inundated & $5(42 \%)$ \\
July & 22 & 27 & 49 & inundated & $7(26 \%)$ \\
August & 86 & 57 & 143 & inundated & $19(33 \%)$ \\
September & 1 & & 1 & terrestrial & \\
October & 1 & & 1 & terrestrial & \\
November & & & 0 & terrestrial & \\
December & & &
\end{tabular}

long setae, and plots of the setal length against body width show a considerable but continuous variation in the males. In the females a much narrower range of setal length is shown.

\section{Ecology}

All the individuals were collected from an inundation forest, Igapó. Almost all the specimens were collected from TM50, TM51 or TM52, which were traps on trees catching downward movement. A few were from TM47 (tree traps catching upward movement and a few also from standing crop studies.

Table 2 shows the numbers of individuals found in different months (most were collected in 1976, but a small number from 1977 are also included). This forest is inundated from March/April until August/ September (see Wolf \& Adis 1992 for more information). It can be seen that most individuals were found during the end of the time when the forest was inundated.

The majority of these specimens were captured walking down trees. The single male in May, one female in February and one female in November were found walking up trees. In addition, one male in June and one in July were recorded as part of standing crop surveys, together with one female in February and 7 in June. This suggests that the bulk of the movement down trees takes place in July-September, during the inundation period although towards the end. Presumably this species spends the beginning of the inundation period in the trees, but where it lives the rest of the year is not known.

It is tempting to think that the long setae and the paddle-shaped claw have something to do with the habitat of this species in the forest, which is seasonally inundated. However, the claw shape, although perhaps most pronounced in the males of this species, is also found in S. hebetunguis (details of the habitat of this species are unknown) and perhaps in a less pronounced way in S. tuberculata sp. nov. (see below). The final column in Table 2 indicates the number and proportion of 'long-haired' males in the samples. For this purpose, a 'long-haired' male is considered to be one with setae equal to or more than $0.08 \mathrm{~mm}$ long. From this it is apparent that 'long-haired' males can be found at almost any time of the year. Although more 'long-haired' individuals were found towards the end of the inundated period, this is also when more individuals were collected in general. 
The considerable size range of the males in terms of number of body rings suggests that individuals continue moulting after attaining maturity. However, it cannot be determined from the present collection whether males moult between long and short setal forms, the long setae develop over a series of moults, or they moult into a long (or short) setal form and then continue with this morphology.

See Table 1 for comments concerning differences between this species and others from Brazil.

Siphonophora tuberculata sp. nov.

urn:1sid:zoobank.org:act:2DD9F3C7-6364-4F67-96A7-338B10A9A4DB

Figs $1,7,9 \mathrm{C}$

\section{Diagnosis}

Small, pale species, with claws blunt and slightly expanded but not as clearly paddle-shaped as in S. setaepromissa sp. nov. or S. hebetunguis. Abundant tubercles on head, collum, pro- and metazonites and coxae. Pleurite ventral margin almost straight, hind margin crenulated. Accessory claw short, laterally located on the claw. Anterior gonopods with spines at the apex and a larger seta laterally.

\section{Etymology}

The specific name refers to the abundant tubercles on many parts of the body.

Material examined (total: $4 \widehat{\partial}, 7 \uparrow q$ )

Holotype

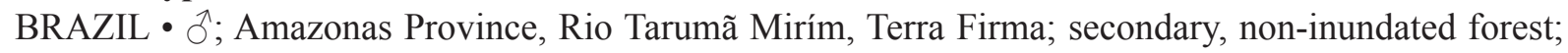
$03^{\circ} 02^{\prime} \mathrm{S}, 60^{\circ} 17^{\prime} \mathrm{W}$; B49; 14 Mar. 1983; Adis and Rodrigues leg.; BTM; arboreal photoeclector B49 BTM BE $\downarrow$; INPA.

\section{Paratypes}

BRAZIL - 1 ㅇ; same collecting data as for holotype; TM K10; Kempson extractor; 23 Nov. 1983; INPA • 1 क ; same collecting data as for preceding; TM K10; Kempson extractor; 23 Nov. 1983; NHML • 1 ; ; same collecting data as for preceding; TM K10; Kempson extractor; 23 Nov. 1983; NHMD • 1 ; ; same collecting data as for preceding; TM E10; ground photo-eclector; 11 Dec.1982; ZMUM • 1 万ै; same collecting data as for preceding; TM K24; 26 Oct. 1982; INPA $\bullet 1$; ; same collecting data as for preceding; TM K16; 30 Jan. 1983; NHMD • 1 ; same collecting data as for preceding; B49 BTM BE $\downarrow$; 14 Mar. 1982; INPA • 1 q; same collecting data as for preceding; 49ATM BE $\downarrow$; arboreal photo-eclector; 1 Feb.1982; INPA -1 क ; same collecting data as for preceding; 49ATM BE $\downarrow$; arboreal photo-eclector; 21 Jan. 1982; INPA • 1 q; same collecting data as for preceding; B49 BTM BE $\downarrow ; 21$ Jan. 1982; INPA.

\section{Description}

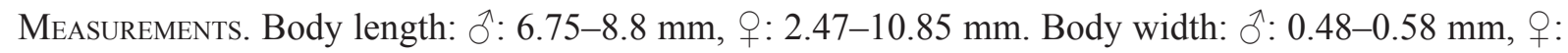
0.3-0.8 mm. Number of podous tergites: $\delta^{\lambda}: 34-43$,, : $16-45$. Number of apodous tergites: $\delta^{\lambda}: 1, q$. 1 .

Colour. Most specimens are pure white, but this may be due to reservation. One female has slightly darker head and first few body rings.

BODY SHAPE. More or less parallel-sided, some appear slightly narrow at the mid-body.

HEAD. In dorsal view lateral edges of head appear to have 'step' between antennal bases and base of rostrum. In lateral view head gently and gradually sloping ventrally, almost flat, with no dome and no abrupt change between rostrum and rest of head. Rostrum more or less straight, flat and barely 
curving downwards. Several individuals with 'mouths' open and under SEM rostrum seems to consist of extension of head capsule above, gnathochilarium below and mandibles to sides. Mandible tip appears to be pointed and mandible itself grooved. Length of rostrum (to antennal base): $\delta^{\lambda}: 0.4-0.46 \mathrm{~mm}$, क: $0.15-0.54 \mathrm{~mm}$. Width of head (between antennal sockets): $\widehat{0}: 0.2-0.26 \mathrm{~mm}$, : $: 0.12-0.24 \mathrm{~mm}$. Abundant setae and tubercles across whole of head capsule. Several long setae on the gnathochilarium, not reaching tip of rostrum, small setae on sides of rostrum right up to tip.

ANTENNAE. Appear to be approximately as long as rostrum, certainly not great deal longer.

Collum. With abundant setae and tubercles, including lots of tubercles along the margin. Wide, with gentle curve to anterior margin and membranous $\mathrm{V}$.

TERGite 2 . Less than $0.5 \times$ length of collum.

Mid-BOdY RINGS. Females of S. tuberculata sp. nov. are separated from those of S. setaepromissa sp. nov. on the graph (Fig. 1) by having fewer rings for their body width. This difference not obvious in males.
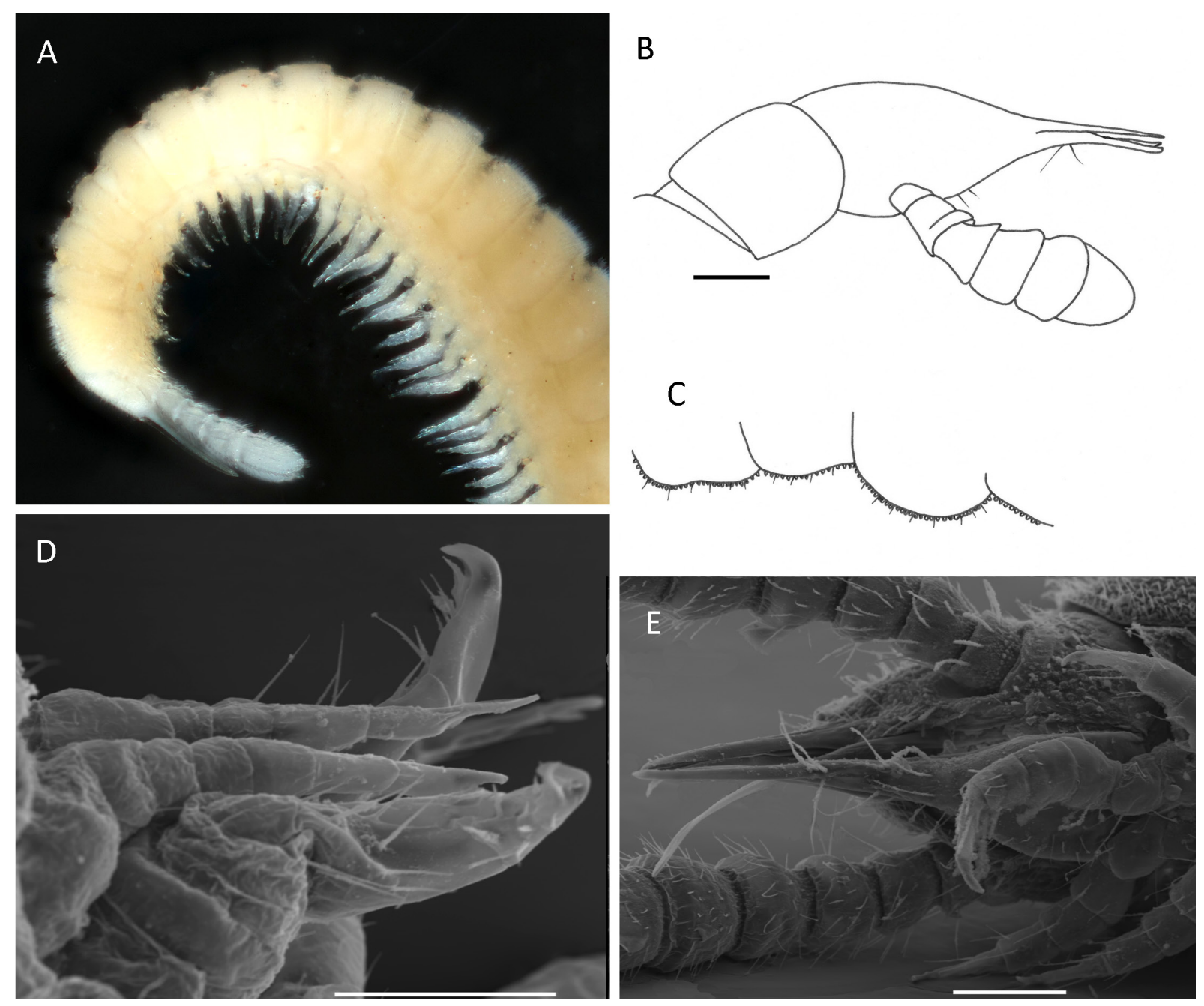

Fig. 7. Siphonophora tuberculata sp. nov., paratype. A. Head and anterior rings, body width approximately $0.5 \mathrm{~mm}$. B. Holotype, head in lateral view. C. Holotype, mid-body pleurites in lateral view. D. Gonopods in situ. E. Head in ventro-lateral view with mandible visible. Scale bars: $B-C=200 \mu \mathrm{m}$; D-E $=100 \mu \mathrm{m}$. 
No obvious paranota. Slightly castellated, perhaps slightly more marked anteriorly, but relatively evenly. Relative width of pro- and metazonites 0.66-0.92 (all but one, 0.8-0.92). Metazonites with abundant tubercles and setae. Prozonites with collapsed tubercles, more pronounced in structure than just cytoscutes, and with no setae. No examples of long setae in any males, of which there were only three. Channel between prozonites and metazonites with a line of setae, but no tubercles. Limbus with a slightly bumpy margin, but not regularly crenulated. Ventral margin of pleurites slightly bilobed on first anterior body rings but subsequently almost straight, with a clearly crenulated margin (under compound microscope) and some setae. Ozopores starting on tergite 5 and finishing on the penultimate tergite, not on protuberances.

LEGS. Length 0.62 of body width ( $(+)$. Length:width ratio of podomeres (prefemur to tarsus) $1.43,1.15$, $1.47,1.38,12.3,3.67$. Coxae with tubercles. Terminal claw slightly enlarged, at least in males, though not as broadly paddle-shaped as in $S$. setaepromissa sp. nov. Accessory claw short, $1 / 4-1 / 2$ length of claw and arising laterally from claw, broad at base.

TELSON. Length:width ratio $0.42-0.77$.

FIRST PAIRS OF MALE LEGS. Appear normal.

ANTERIOR GONOPODS. Impossible to count segments due to apparent fusion. Overall shape slightly angular in lateral view. Mesal lobe may or may not be present (ambiguous in some SEM images, not visible in others). Some setae on basal segments on the posterior side, not possible to see clearly on anterior side. Tip hook-like, both in overall shape, which is strongly tapered, and at very apex, which is pointed, ending in a claw. Setae on last segment strong and broad-based, but not ribbon-like except for one closest to tip, which is on lateral side, is parallel-sided, slightly uneven in direction and not as large as that on mesal side of $S$. setaepromissa sp. nov., although still reaching to tip of anterior gonopods.

POSTERIOR GONOPODS. Probably with 7 segments including the coxae, with no apparent setae on basal segments. Overall shape more parallel-sided than in S. setaepromissa sp. nov. Apical segment with a single accessory seta, but perhaps slightly smaller than in S. setaepromissa sp. nov. At point of insertion of seta the segment narrows abruptly. In SEM illustrated here posterior gonopods are both broken, but a different SEM mount shows they are unevenly twisted, less like a taut streamer and more like one blowing in the wind. The posterior gonopods of this specimen may also be broken, possibly with a forked tip.

\section{Ecology}

This species was found at the same locality and habitat as Columbianum nahvalr Read \& Enghoff, 2018. Most of the specimens were from the soil and extracted using a Kempson apparatus between October and January. Three females and a male were caught in downward catching photo-eclectors in January, February and March. This is a non-inundated area, but clearly this species spends time in trees as well as in the soil.

\section{Siphonophora species indet.}

\section{Material examined (total 1 q)}

BRAZIL • 1 9; 'Amazonas Province, BR174, HW70, 160/01'; 23 Sep. 1996; [thought to be primary forest at Reserva Duche]; INPA.

This specimen has a head shape that puts it in Siphonophora, but it has been preserved in a very contracted state and it is very difficult to clearly see any details. It is quite tuberculate, but as it is a female there are 
no gonopods to compare with the other species described here. In the absence of any further specimens this has not been assigned to a species here.

\section{Discussion}

\section{Evaluation of the relevant nominal genera}

(See Table 3 for a list of previously described species examined during this study.)

\section{Cordillerium Verhoeff, 1941}

The genus Cordillerium was erected by Verhoeff (1941) in his geographic and systematic review of the Siphonophorida for Siphonophora fuhrmanni Carl, 1914. Carl (loc cit.) originally described S. fuhrmanni, S. columbiana and S. gracilicorne, all from Columbia, placing them in Siphonophora because of the presence of sensory pits on antennomeres 5 and 6 (following the description in Attems 1900 of S. brauri and S. tropiphora). Siphonophora gracilicorne has a very different head shape and is now considered as a species of Columbianum (Read \& Enghoff 2018). In the key of Verhoeff (1941), Cordillerium is distinguished on gonopodal characteristics, by having over 100 body rings and antennomeres 3-5 'wine glass-shaped' as long as wide (as in Okeanozonium Verhoeff, 1941). Neither the gonopods nor the number of body rings has been found to be particularly reliable in the present study, although the relative length/width of antennomeres may be helpful. In the same key, Siphonophora is distinguished, again on the basis of gonopod segments and number of body rings.

Cordillerium fuhrmanni (Fig. 8A) was the only species in the genus according to Verhoeff (1941). Jeekel (2001) listed it under 'Siphonophora from America', thus synonymising Cordillerium with Siphonophora, but making no further comment about the species or genus. Examination of the type specimens shows many similarities to the species in the current collection. The head shape and short, broad antennae are similar, although the rostrum does seem quite short. A walking leg was illustrated by Carl (1914) and shows a small accessory claw, which he described from the mid-body legs as being small and barely more than $1 / 3$ of the length of the claw. Examination of the types reveals that the claw appears rather broad and the pleurites in the mid-body are strongly notched. However, one striking feature is the presence of long setae in the male (not referred to in the original description). These are mixed in with shorter setae, with the longer ones at the edges of the tergal ridges and the short in the middle, giving a very ragged-looking appearance. However, the types were rather larger than those described here as Siphonophora setaepromissa sp. nov., and the habitat is very different: at $1820 \mathrm{~m}$ in the central Columbian Cordillera. Thus, it seems unlikely that this is the same species, although it could be closely related.

\section{Pterozonium Attems, 1951}

Is Rhinosiphora hebetunguis actually a species of Pterozonium as Jeekel (2001) tentatively suggested? The key of Attems (1951) separates out Pterozonium at the first couplet. "Lateral paranota present, lateral parts of the metazonite don't follow the arch of the back but remain horizontal" and the alternative is "back regularly arched, without paranota". This distinction (presence/absence of paranota) is the same that Verhoeff (1924) used to distinguish Rhinosiphora from Siphonophora. Mauriès (1980) noted that Pterozonium as understood by Attems (1951) is very close to Siphonophorella Attems, 1951, and that there were no real differences in the gonopods between these two genera. He suggested that they were synonymous and differences between the relative size of the paranota not sufficient to consider them separate. Jeekel (2001) formally synonymised Siphonophorella with Pterozonium, quoting the similarities of two species from the Seychelles (braueri Attems, 1900 and tropiphorum Attems, 1900) and that the presence/absence of lateral tergal extensions is not sufficient to assign them to different genera. However, the six species he assigned to this genus seem rather a 'rag bag' of different forms and thus this genus does not seem to have a clear identity. The type species, $P$. tropiphorum, described by 
Table 3. Siphonophorid specimens studied for comparison with the new Brazilian material.

\begin{tabular}{|c|c|c|c|c|}
\hline Nominal species & $\begin{array}{l}\text { Number and } \\
\text { gender of } \\
\text { specimens }\end{array}$ & $\begin{array}{l}\text { Type } \\
\text { status }\end{array}$ & Geographical origin & Repository \\
\hline $\begin{array}{l}\text { Rhinosiphora hebetunguis } \\
\text { Attems, } 1951\end{array}$ & $6 \partial^{\lambda}, 2$ 우 & types & $\begin{array}{l}\text { BRAZIL, Taperinha near } \\
\text { Santerem }\end{array}$ & NHMW \\
\hline $\begin{array}{l}\text { Siphonophora fuhrmanni } \\
\text { Carl, } 1914\end{array}$ & $1 \stackrel{\lambda}{,}, 1$ q & types & $\begin{array}{l}\text { COLUMBIA, Camelia } \\
\text { Angelopolis, Central } \\
\text { Cordillera, } 1820 \mathrm{~m}, \\
\text { coffee plants }\end{array}$ & NHML \\
\hline $\begin{array}{l}\text { Siphonophora mjoebergi } \\
\text { Verhoeff, } 1924\end{array}$ & 1 q & not type & AUSTRALIA & NHML \\
\hline $\begin{array}{l}\text { Siphonophora longirostris } \\
\text { Silvestri, } 1895\end{array}$ & $1 q$ & not type & SINGAPORE, Botanic gardens & NHML \\
\hline
\end{tabular}
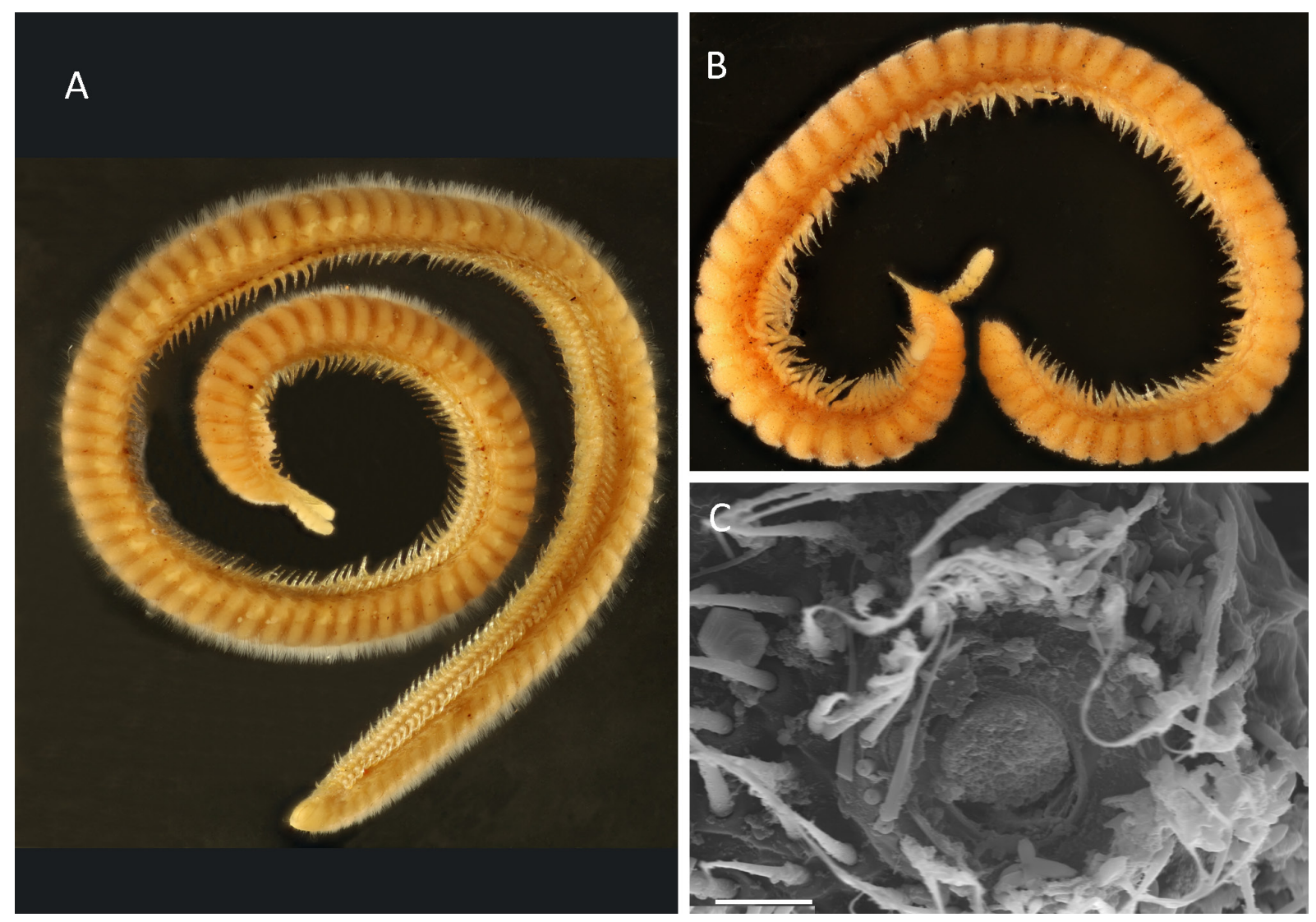

Fig. 8. A. Siphonophora fuhrmanni Carl, 1914, type specimen, habitus, body length approximately $30 \mathrm{~mm}$. B. Siphonophora mjoebergi Verhoeff, 1924, non-type specimen, habitus, body length approximately $15 \mathrm{~mm}$. C. Siphonophora setaepromissa sp. nov., paratype, ozopore showing ring of setae, scale bar $=0.01 \mathrm{~mm}$. 
Attems in 1900 as Siphonophora tropiphora and designated as the type species of Pterozonium by him in 1951, is from the Seychelles. It clearly has enlarged paranota, and the gonopods also differ from those of hebetunguis by having an expanded flange at the tip of the posterior gonopods and a crab-claw like pair of claws on the end of rather elongated anterior gonopods. Whether these characters are sufficient to warrant a distinct genus will only be clear after further study, but hebetunguis is sufficiently different that is cannot easily be assigned to this genus by comparison with P. tropiphorum. It seems that hebetunguis is probably not in the genus Pterozonium according to the current understanding of the genus.

\section{Rhinosiphora Verhoeff, 1924}

Rhinosiphora is primarily an Australasian genus (originally described as a subgenus of Siphonophora for S. mjoebergi Verhoeff, 1924, Fig. 8B). The type species was described in detail, and the original illustrations show a gradual-headed species, without paranota, but with tuberculate collum and metazonites. The antennae are perhaps longer and narrower than in the new species described here. The main distinguishing feature seems to be the anterior gonopods that are even more reduced and simple than in most siphonophorids and were considered to consist of just 4 segments with an apical zone supporting a few small setae and simple rounded tips. Verhoeff (1924) also included a key to distinguishing the subgenera, which gives the distinguishing feature as the presence of tubercle-like wings projecting out and backwards from the tergite (what we would now call paranota), especially in the posterior half of the trunk in Siphonophora s.str. which are lacking (or simply bulges) in Rhinosiphora. Verhoeff (1941) later elevated the subgenus Rhinosiphora to generic status. His key to distinguish Rhinosiphora again stressed the simple nature of the anterior gonopods with just 3-4 segments. Non-type specimens of $R$. mjoebergi were examined here and these appeared to be lacking any paranota. The head shape was clearly gradual, with a sinuous lateral margin, and the rostrum relatively short and straight. The pleurite margin was barely curved and the claw appeared normal.

Examination of the type series of $R$. hebetunguis shows it to be similar in respect to the illustrations of the original description, and the anterior gonopods certainly seem to be very squat and broad. The possibility exists that the gonopods may be immature and lack definition, segments and apical structures on the anterior gonopods. This could mean that Rhinosiphora is a 'false' genus based on a species described from subadult males. However, all the six male specimens of the type series of hebetunguis appear to have similar gonopods, while the individuals do vary in size, suggesting that the gonopods are not immature.

The specimens examined from Amazonia do not have paranota, although the ozopores can sometimes appear to be on small protuberances. Thus, by this character they appear closer to Rhinosiphora than Siphonophora, but see comments under the genus Siphonophora.

Rhinosiphora hebetunguis was described from Taperinha near Santarem (Brazilian Amazonas) in 1951 by Attems, who provided a key to the six species he considered to be in this genus (Rhinosiphora mjoebergi Verhoeff, 1924 from Australia; R. cylindrica Verhoeff, 1941 from the Caroline Islands; R. nodulosa Verhoeff, 1924 from Australia; $R$. nasuta Verhoeff, 1924 from Australia; $R$. hebetunguis and $R$. scnipophaga Attems, 1951, described as new in this paper from Pulau Berhala, Indonesia). Rhinosiphora cylindrica was originally described in the genus Okeanozonium Verhoeff, 1941, but transferred to Rhinosiphora by Attems (1951). Attems (loc. cit.) did not explain why he placed hebetunguis in Rhinosiphora, but his key separates out this genus first as lacking paranota and with an arched shape in cross section; then on details of the gonopods, with the anterior gonopods of Rhinosiphora having 3-4 articles and the last one small and not in the form of a claw. These characters do appear to agree with the definition of the genus Rhinosiphora by Verhoeff (1924), although the geographical range increased substantially with the inclusion of a species from south America. 
The original description of $R$. hebetunguis (Attems 1951) includes an illustration of a broadened claw, described as being obtuse and spoon-like. The original description of $R$. mjoebergi (Verhoeff, 1924) states that the claw is simple, with a small accessory claw. The significance of a widened claw is, as yet, unknown, but it is striking that the species in the current collection all show some widening of the claw, and it may be that this is a generic character which would distinguish them from R. mjoebergi.

Jeekel (2001) in his complete bibliographical review of the siphonophorids, listed $R$. mjoebergi in Rhinosiphora, but stated that the Australian species probably each deserve separate generic status. Rhinosiphora scnipophaga is listed under Pterozonium which, from the lateral paranota of the type description, seems appropriate. Rhinosiphora hebetunguis is listed under Siphonophora by Jeekel as being difficult to interpret, and he suggests that it may be related to species of Pterozonium Attems, 1951. This may be because in the original description Attems stated that the pores are on small bosses, and Jeekel subsequently interpreted these to be small paranota. In fact, as Shelley (1996) also noted, specimens that are preserved in a dried state, or have even contracted during the preservation period, can appear to have prominent ozopores when normally these would be flush with the cuticle and perhaps distinguished by a ring of setae as in Fig. 8C.

\section{Siphonophora Brandt, 1837}

Shelley (1996) redescribed the type species, Siphonophora portoricensis Brandt, 1837, including new illustrations. This species is important because it is the type species of the type genus and the oldest species name in the order. The illustrations show a gradual head shape in profile very much like the species described here. In dorsal view, the sides of the head are rather triangular and slightly sinuous, or 'stepped', where the antennae are inserted, and the rostrum is relatively short. The whole head and body is thickly clothed with setae, and the description is detailed, although there is no information about the pleurites or the extent of the tubercles. Jeekel (2001) stated of hebetunguis that "it is evident that the species is not congeneric with $S$. portoricensis", a comment which seems to have been made in relation to the anterior gonopods. Shelley drew the gonopods of the lectotype of S. portoricensis, which appears to lack the characteristic large spine on the posterior gonopods, but the figure caption states that the setae are not drawn, so it may in fact just have been omitted. The posterior gonopods are 4-segmented in S. portoricensis and those of R. hebetunguis are said to be 3- or 4-segmented (Attems 1951), although fusion of the segments makes this difficult to be sure about. Shelley (1996) had some fresher material of S. portoricensis, but the illustrations of the gonopods are only of the types. Siphonophora portoricensis is, according to Shelley, characterised by the fusion of the distal three podomeres of the anterior gonopods. We would here suggest that the fusion of the podomeres occurs in many siphonophorids, but the extent is very difficult to see, even in SEM, and so is a difficult character to use generally and probably unreliable as a species diagnosis. Siphonophora portoricensis does not appear to have large paranota, suggesting that the distinction by Verhoeff (1941) between Rhinosiphora and Siphonophora on the basis of paranota may not have any validity. Thus, there appears no obvious reason why hebetunguis is not a species of Siphonophora.

The only other species of siphonophorid described from Brazil is $S$. pubescens Schubart, 1947, which appears from the original description to have a gradual lateral margin to the head. Jeekel (2001) listed this as a species that should probably be excluded from the genus Siphonophora on the basis of the very different form of the anterior gonopods, which are deeply split into two separate blades. In other respects this species appears similar to those in the present study.

While it seems highly likely that there are several different genera within the family Siphonophoridae that have previously been considered as the genus Siphonophora, reliable characters for distinguishing them have yet to be elucidated, and the validity of others needs testing. We do not know enough either 
about the global distribution of siphonophorid genera to know if a genus from Australia is also likely to be found in South America.

Within our current understanding, the species in focus here show varying degrees of claw expansion, unlike R. mjoebergi, and thus the genus Rhinosiphora does not seem appropriate for them. One of the new species shows 'pilosity dimorphism' similar to Siphonophora fuhrmanni, but there is no evidence that the other new species shares this trait; therefore, Cordillerium is not the appropriate genus. Therefore, the large genus Siphonophora seems the best possibility at the current time, while we acknowledge that this adds yet more species to this poorly-defined genus. It may be that the claw structure is a valid generic character and that a separate genus is warranted, but currently sufficient justification for this is lacking.

\section{Claw shape and other morphological characters}

Claws were looked at in the two new species and the types of S. hebetunguis from NHMW using entire specimens under a compound microscope as well as legs mounted on slides. All three species had claws that were more or less paddle-shaped; however, the extent was very variable between specimens. Generally, the expanded shape was more marked in males and in the anterior legs; they were most pronounced in the largest males. Figure 9 shows how the claw shape varied in different individuals of the same species. In $S$. setaepromissa sp. nov. the accessory claw was generally fairly long and arose ventrally from the claw. In $S$. hebetunguis and $S$. tuberculata sp. nov. the accessory claw arose from the lateral side of the claw and it was therefore quite difficult to be sure that the claw was viewed laterally; thus, some of the views may be closer to ventral. The SEM images (Figs 2F, 6D) show some of these aspects in more detail. In many of the claws a small triangular area was visible at the base which appears to be an internal part of the claw and not a separate structure.

The cuticular tubercles in these species are sometimes fully expanded and clearly visible, but sometimes they collapse and deflate. In a collapsed state they can vary from a round shape to a crescent. Cytoscutes, i.e., cuticular 'cells' each corresponding to a hypodermis cell (Fusco et al. 2000) are also evident. The difference between simple cytoscutes and tubercles is just a matter of size and degree of expansion, so it can be a little difficult to determine if part of the exoskeleton is tuberculate or not, especially using a light microscope. Generally, the cytoscutes appear with small wrinkles at the margins of the cells, whereas tubercles when collapsed have more extensive wrinkling and remaining structure. The tubercles are not associated with setal bases (as previously thought for some species), although the bases of the setae can give the area a rugged appearance which, using a light microscope, can be difficult to distinguish from a very tuberculate area. The tubercles appear to be most intact at the hind margin of the metazonites, near the limbus, and there appears to be a gradual progression of development and destruction. Some specimens had anchor-shaped tubercles when viewed under SEM (Fig. 5D).

As a result of this work a few additional characters to those evaluated in Read \& Enghoff (2009) can be added to the list of those worth exploring in future studies of siphonophorid taxonomy:

- Pro- and metazonite, in terms of details of tubercles and setae.

- Details of the 'channel' between the pro- and metazonite.

- Presence/absence of paranota (as opposed to small protuberances where the ozopores are located).

- Relative length of collum and next body ring.

- Shape of the mandible tip.

We did not find any useful variation in the form of the telson or subanal scale in this group of species.

It is recommended that the gonopods should be examined intact, still attached to the sternite, and under SEM. Once they are detached it is almost impossible to orientate them and they are also easily lost as 
they are so small. Without SEM (and even sometimes with it) it is difficult to see the mesal side of the gonopods but separating the two mesally is not possible without detaching them from the sternum.

\section{Pilosity polymorphism}

The very long, unruly pilosity of some males seems to be peculiar to $S$. setaepromissa sp. nov. We have checked original descriptions and/or supplementary descriptions of almost all the species of Siphonophorida listed by Jeekel (2001), in addition to studying type specimens of quite a number of species, cf. above. Many of the original descriptions are quite poor, but one would think that such a long pilosity as seen in $S$. setaepromissa sp. nov. would have been noted. The only suggestions of anything similar to the situation in $S$. setaepromissa sp. nov. concern the following species:

Gonatotrichus silhouettensis (Mauriès, 1980) from the Seychelles Islands in which according to Mauriès (1980) the body rings have a "double" pilosity: a dense cover of numerous small hairs plus 1-3 three rows of "macrochètes".
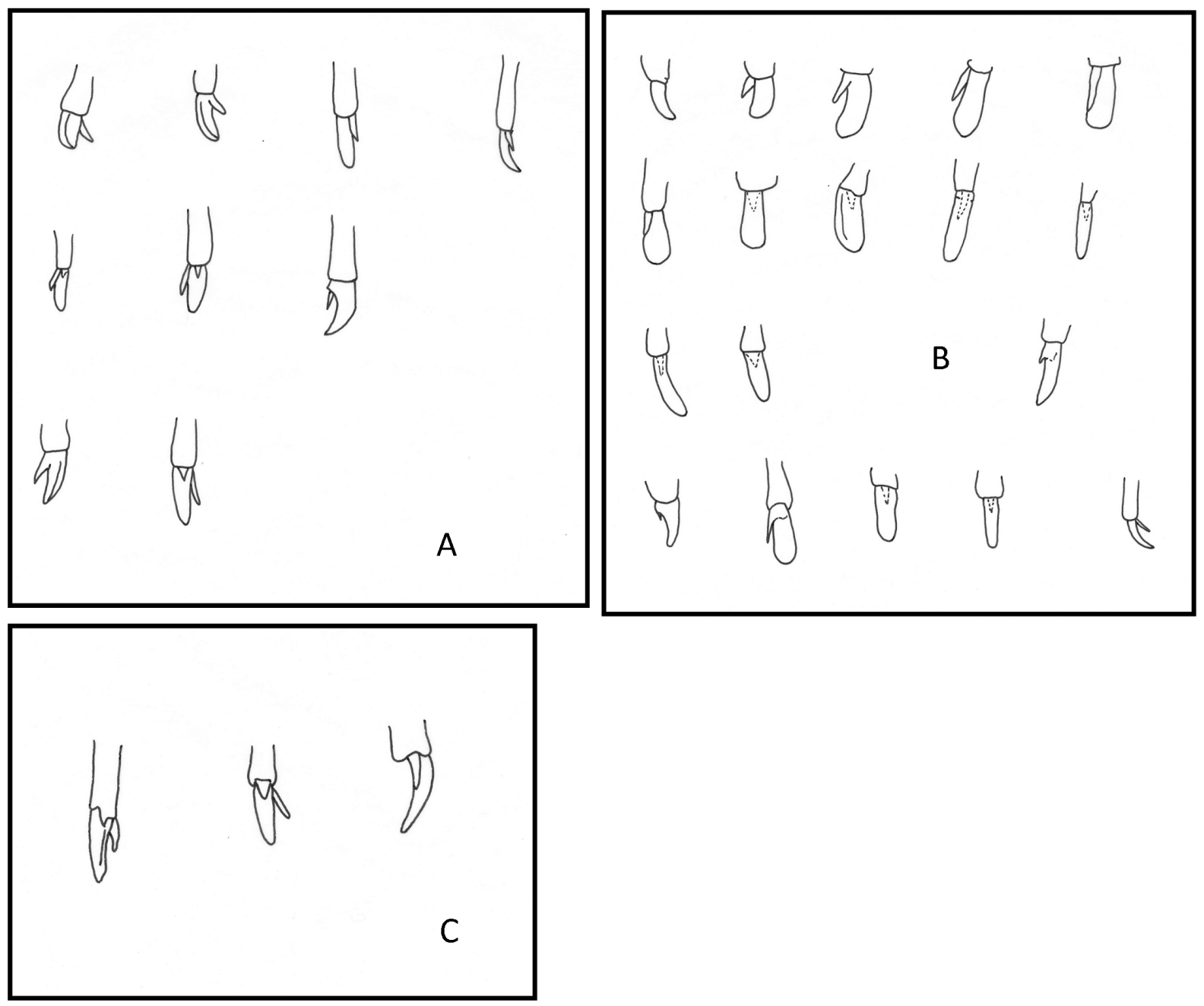

Fig. 9. Claws and accessory claws in the three species of Siphonophora Brandt, 1837 studied here. A. Siphonophora hebetunguis (Attems, 1951). B. Siphonophora setaepromissa sp. nov. C. Siphonophora tuberculata sp. nov. Not to scale. 
Siphonophora albiceps Loomis, 1970 from the U.S. Virgin Islands, of which Loomis (1970) wrote: "Surface of head, segment 1, and metazonites with quite a dense mixture of erect setae of variable length in subequal numbers, the longest approximating the length of the metazonites, shortest a fifth or sixth as long"

Siphonophora villosa Attems, 1938 from Vietnam in which the body ring setae are "significantly longer than in all other species known to me, such that this species this way is easy to recognize" (Attems 1938, translated from German).

No mention has been found, however, of a pilosity difference between males and females, nor of a difference in setal length between conspecific males. The function of the long setae is, of course, unknown, as so much else concerning siphonophorids.

\section{Distinguishing the species of Siphonopora from Brazil}

Table 1 shows the characteristics of each of the species described from Brazil together with S. portoricensis (the type species of the genus).

Note that Siphonophora paulistus Schubart, 1945 was considered by Read \& Enghoff (2018) to be a member of the genus Columbianum because of the head shape. Neither this species or others of the genus Columbianum are included in Table 1. See also Fig. 1 illustrating the variation in number of rings against body width in some of these species.

\section{Conclusion}

Examination of the large collection of Siphonophoridae from studies of the late Joachim Adis has contributed greatly to our knowledge of the family. While some species could be relatively straightforwardly attributed to the genus Columbianum, those with a more gradual lateral margin to the head and a less obvious distinction between the head and rostrum remain exceptionally difficult. The pale colour, soft body structure, abundance of setae and tendency to collect dirt means that observations using a light microscope are difficult, as can be seen in the quality of the photographs. SEM is helpful but has limits when there are small numbers of specimens available. Features that are relatively easy to see frequently seem to be unreliable, while those that may be better are frequently difficult to see. Reliable characters continue to remain elusive for this group and those used in the present study are not considered particularly good. There remains a high likelihood for future synonymies and re-assignment of species within genera. Study of fresh material for genetic analysis and exploration of further variations within species would be beneficial.

\section{Acknowledgements}

This project would simply not have been possible without the help and encouragement of the late Joachim Adis (1950-2007), with whom we are very fortunate to have collaborated. Work in Plön (by HR) was supported by the Max-Planck-Institute für Limnologie, Plön, and she is grateful to all those that assisted during her stay. Work in Copenhagen (by HR) was supported by a grant from the European Commission's (FP 6) Integrated Infrastructure Initiative programme SYNTHESIS (DK-TAF). Sergei Golovatch (Institute for Problems of Ecology and Evolution, Russian Academy of Sciences) and Hans Reip (Senckenberg Museum für Naturkunde Görlitz) assisted greatly with literature and Sergei Golovatch commented on the manuscript, especially regarding the ecological remarks. Verena Stagl (NHMW) kindly loaned the specimens of S. hebetunguis. Jan Beccaloni and Rachel Clarke permitted access to specimens at the Natural History Museum in London, and Florin Feneru and Chris Raper from the Angela Marmont Centre helped with taking photographs. HR would also like to thank the late Steve 
Hopkin (1956-2006) for assistance at an early stage in this work including SEM studies and Mark Frater who continues to provide support and encouragement.

\section{References}

Attems C. 1900. Dr. Brauer's Myriapoden-Ausbeute auf den Seychellen im Jahr 1895. Zoologische Jahrbücher (Systematik) 13: 133-171. Available from https://biodiversitylibrary.org/page/10197407 [accessed 20 Jan. 2019].

Attems C. 1938. Die von Dr. C. Dawydoff in französich Indochina gesammelten Myriapoden. Mémoires du Muséum national d'Histoire naturelle, Nouvelle Série 6: 187-353.

Attems C. 1951. Révision systématique des Colobognata (Myriapodes Diplopodes) et description d'espèces nouvelles. Mémoires du Muséum national d'Histoire naturelle, Série A III (3): 193-231.

Carl J. 1914. Die Diplopoden von Columbien, nebst Beiträgen zur Morphologie der Stematoiuliden. Mémoires de la Société neuchâteloise des Sciences naturelles 5: 821-993.

Fusco G., Brena C. \& Minelli A. 2000. Cellular processes in the growth of lithobiomorph centipedes (Chilopoda: Lithobiomorpha). A cuticular view. Zoologischer Anzeiger 239: 91-102.

Jeekel C.A.W. 2001. A bibliographic catalogue of the Siphonophorida (Diplopoda). Myriapod Memoranda III: 44-71.

Loomis H.F. 1970. Millipedes of St. John, U.S. Virgin Islands, and a new species from Puerto Rico. Florida Entomologist 53: 129-134.

Mauriès J.-P. 1980. Contributions a l'étude de la faune terrestre des îles granitiques de l'árchipel des Séchelles. Myriapoda - Diplopoda. Revue de Zoologie africaine 94: 138-168.

Read H.J. \& Enghoff H. 2009. The order Siphonophorida - A taxonomist's nightmare? Lessons from a Brazilian collection. Soil Organisms 81 (3): 543-556.

Read H.J. \& Enghoff H. 2018. Siphonophoridae from the Brazilian Amazonia. Part 1 - The genus Columbianum Verhoeff, 1941 (Diplopoda, Siphonophorida). European Journal of Taxonomy 477: 1-23. https://doi.org/10.5852/ejt.2018.477

Schubart O. 1947. Os Diplopoda da viagem do naturalista Antenor Leitão de Carvalho aos Rios Araguaia e Amazonas em 1939 e 1940. Boletim do Museu Nacional do Rio de Janeiro (Nova Série, Zoologia) 82: $1-74$.

Shelley R.M. 1996. A description of Siphonophora portoricensis Brandt (Diplopoda: Siphonophorida: Siphonophoridae), with a catalogue of ordinal representatives in the New World. Journal of Natural History 30: 1799-1814. https://doi.org/10.1080/00222939600771051

Verhoeff K.W. 1924. Results of Dr. E. Mjöberg's Swedish Scientific Expeditions to Australia 19101913. 34. Myriapoda: Diplopoda. Arkiv för Zoologi 16 (5): 1-142.

Verhoeff K.W. 1941. Versuch eines Siphonophoriden-Systems und geographisch-phylogenetische Beurteilung der Gonopoden. Zoologischer Anzeiger 134: 212-224.

Wolf H.G. \& Adis J. 1992. Genetic differentiation between populations of Neomachilellus scandens inhabiting neighbouring forests in Central Amazonia (Insecta, Archaeognatha). Verhandlungen des naturwissenschaftlichen Vereins Hamburg (NF) 33: 5-13. 
Published on: 7 February 2019

Topic editor: Rudy Jocqué

Desk editor: Kristiaan Hoedemakers

Printed versions of all papers are also deposited in the libraries of the institutes that are members of the EJT consortium: Muséum national d'Histoire naturelle, Paris, France; Meise Botanic Garden, Belgium; Royal Museum for Central Africa, Tervuren, Belgium; Royal Belgian Institute of Natural Sciences, Brussels, Belgium; Natural History Museum of Denmark, Copenhagen, Denmark; Naturalis Biodiversity Center, Leiden, the Netherlands; Museo Nacional de Ciencias Naturales-CSIC, Madrid, Spain; Real Jardín Botánico de Madrid CSIC, Spain; Zoological Research Museum Alexander Koenig, Bonn, Germany. 